\title{
Who ate the birds: the taphonomy of Sarakenos Cave, Greece
}

\author{
Zbigniew M. Bochenski ${ }^{1}$ - Teresa Tomek ${ }^{1} \cdot$ Krzysztof Wertz $^{1}$ • \\ Malgorzata Kaczanowska $^{2}$ - Janusz K. Kozlowski ${ }^{3}$ - Adamantios Sampson ${ }^{4}$
}

Received: 14 October 2016 / Accepted: 8 March 2017 / Published online: 20 March 2017

(C) The Author(s) 2017. This article is published with open access at Springerlink.com

\begin{abstract}
The taphonomic analysis of avian remains from Sarakenos Cave reveals that, contrary to previous suggestions, many bird bones excavated there represent food remains of the Eagle Owls rather than humans. The conclusion is based on the presence of traces of digestion, beak and claw punctures, and indirect evidence that includes relative preservation of particular elements, species composition, the lack of cut marks, and the absence of numerous traces of burning. Specimens with medullary bone and traces of digestion indicate that the owls killed breeding females in spring. Since it is unlikely that owls shared the cave with humans at the same time, it supports the notion based on archeological evidence that human groups did not inhabit it permanently.
\end{abstract}

Keywords Avian remains · Eagle Owl · Sarakenos Cave · Paleolithic $\cdot$ Mesolithic $\cdot$ Neolithic

\section{Introduction}

Sarakenos Cave is the largest of numerous caves on the shore of the former Kopais Lake, Boeotia, Greece (Fig. 1). The lake was (partly) drained several times-the first time in the

Zbigniew M. Bochenski

bochenski@isez.pan.krakow.pl

1 Institute of Systematics and Evolution of Animals, Polish Academy of Sciences, Slawkowska 17, 31-016 Kraków, Poland

2 Archaeological Museum, Ul. Senacka 3, Kraków, Poland

3 Institute of Archaeology, Jagiellonian University, Ul. Gołęia 11, 31-007 Kraków, Poland

4 Department of Mediterranean Studies, University of the Aegean, 1 Demokratias Ave, 85100 Rhodes, Greece fourteenth century BC and permanently in the twentieth century AD. Sarakenos Cave is situated at an elevation of about $100 \mathrm{~m}$ above the level of the former lake; the entrance to the cave, which is facing southwest, is $25 \mathrm{~m}$ broad and 3-4 m high and provides good light in the cave and an unobstructed view toward the Kopais basin (Kaczanowska et al. 2016b; Sampson 2008a). In the recent past, the cave was used as a sheep pen, which resulted in a layer of dung covering the floor.

Archeological records indicate that Sarakenos Cave was visited sporadically by human groups during the Final Paleolithic, but it changed during the Mesolithic and Early Neolithic when human visits were more frequent (Kaczanowska et al. 2016a). The results of the first exploration of the cave that began in the 1970s (Spyropoulos 1973) were never published and the stratigraphical data were lost. Systematic excavations in Sarakenos Cave have been conducted since the mid-1990s (Sampson 2008b; Sampson et al. 2009, 2010; Kaczanowska et al. 2016b). The stratigraphic sequence was reconstructed in trench A where 12 layers were distinguished, Middle Paleolithic (12-11), Final Paleolithic (10-5), Mesolithic (4), Initial Neolithic (3), Early Neolithic (2), and younger deposits (Late Neolithic, Early Bronze Age). Layers 10-2 yielded several thousand animal bones. The most numerous animal remains in the Final Paleolithic and Mesolithic deposits (10-4) were those of birds followed by rodents, whereas in the Neolithic layers (3-2), medium-sized ruminants predominated. Molluscs, fish, amphibians, and reptiles were scarce in all layers (Wilczyński et al. 2016a, b).

Layers 10-5 (Final Paleolithic) formed between $12,220 \pm 60$ and $9940 \pm 60$ BP. Over this period, the cave was visited several times by Epigravettian hunters, whose traces were recorded in the form of a small series of artifacts, numbering from 3 to 40 pieces, depending on the layer, and a small number of mammal bones including European hare (Lepus europaeus), wild ass (Equus hydruntinus), aurochs 


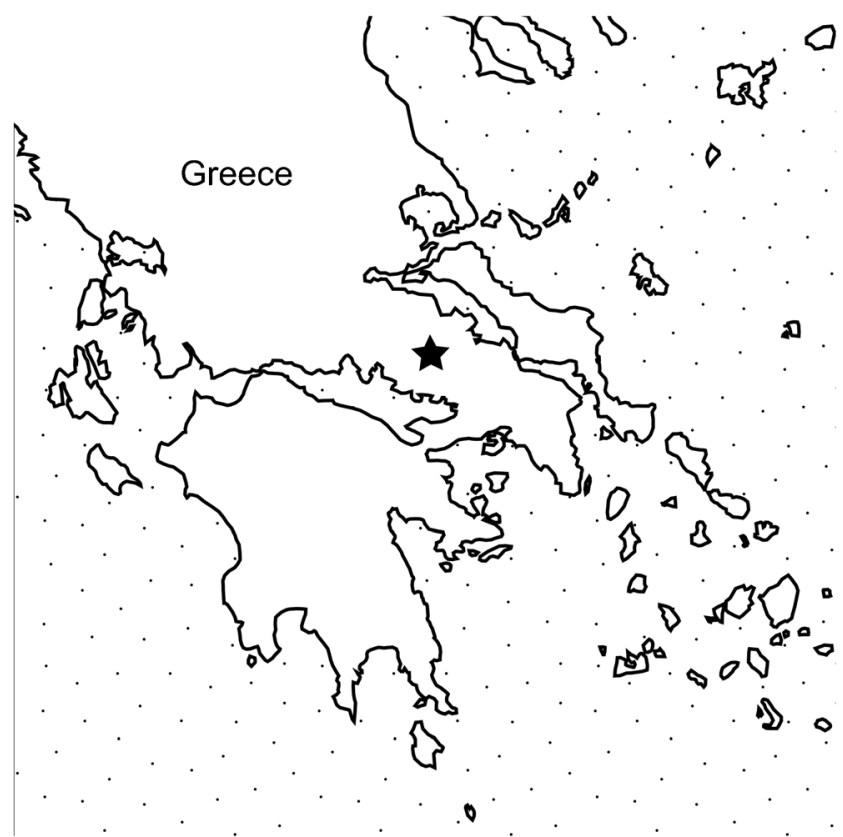

Fig. 1 Location of Sarakenos Cave at the shore of the former Kopais Lake, Boeotia, Greece

(Bos primigenius), and wild boar (Sus scrofa). Bird remains, especially those of the rock partridge (Alectoris graeca) and pigeons (Columba cf. livia), were much more numerous. In the uppermost part of the Final Paleolithic sequence (layer 5), a horizon of hearths was recorded.

The formation of the Mesolithic layer (4) took place between $8590 \pm 50$ (bottom) and the interval between $7780 \pm 40$ and $7950 \pm 40 \mathrm{BP}$ (top). Despite its considerable thickness, traces of human visits are very modest in layer 4 and represent a specific flake industry, different from the majority of Mesolithic industries known from continental Greece and resembling rather the lithic phase VII from Franchthi Cave (Perlès 1990). Bones of mammals which were hunted were scarce in layer 4; they included European hare, wild boar, and Cervidae. Numerous bird remains included mainly pigeons and starlings (Sturnus vulgaris). Micromorphological analysis of this layer revealed the presence of a considerable amount of plant remains. Layers 4 and 3 were separated by a hearth horizon, which produced a small number of artifacts.

Of particular interest are the contents of layer 3, which formed between $7960 \pm 40$ (boundary between layers 3 and 4) and $7570 \pm 50 \mathrm{BP}$ (boundary between 2 and 3). The lithic inventory from that layer represents a local flake tradition, a result of adaptation to local raw materials of poor quality (silicified limestone and quartz), but at the same time, single obsidian blades are present and bones of domesticated animals (Capra hircus/Ovis aries-goat/sheep) are vastly predominant among mammal remains. This, as well as the discovery of single fragments of pottery, suggests possible contacts with groups distinguished by a food-producing economy. Pigeons predominated among the scarce bird remains.
The Early Neolithic in the fully developed form is represented by the finds from layer 2 , dated between $7570 \pm 50$ and $7400 \pm 35$ BP. In that period, the cave served as a short-term shelter for herdsmen. Mammal remains from this layer are predominated by goat/sheep $(C$. hircus $/ O$. aries $)$, with trace amounts of bones belonging to cattle (Bos taurus) and domestic pig ( $S$. scrofa f. domestica). Bird remains were scarce; pigeons dominated them. In terms of taxonomy, pottery and lithic artifact layer 2 refers to Early Neolithic communities from Thessaly.

Altogether, five trenches (A, B, C, D, and E) were excavated in Sarakenos Cave (Kaczanowska et al. 2016b; Sampson et al. 2009). Environmental and climatic changes that are reflected in the species composition were already summarized in a previous study based on remains from trench A (Wilczyński et al. 2016a, b). Here, we focus on the taphonomy of the bird remains and we include remains excavated so far from trenches A and D, i.e., those with reliable stratigraphy. The goal of the paper is to establish the most likely agent that was responsible for the accumulation of avian bones at Sarakenos Cave. Were the birds hunted and eaten by humans or raptors, or did they die of natural causes?

\section{Material and methods}

A total of 3890 avian remains were recovered from Sarakenos Cave. Most of them were found in trench A (number of identified specimens $(\mathrm{NISP})=2928$ ), and the remaining come from trench D (NISP $=962)$. All skeletal elements are represented, including vertebrae and phalanges. The remains date from the Paleolithic through Neolithic and they represent 88 taxa (Wilczyński et al. 2016a; unpublished data from trench D) that were identified using the comparative skeletal collection at the Institute of Systematics and Evolution of Animals, PAS, in Krakow and identification manuals (Bochenski and Tomek 2009; Tomek and Bochenski 2000, 2009). For the purpose of this study, we discarded all unidentified bones and those with uncertain dating. Moreover, for the sake of uniformity, we limited our study to more numerous taxonomic and skeletal groups (major long bones of more numerous groups of birds; see below), which left us with well over 2000 specimens to study. Other avian taxa (grebes, charadriforms, rails, bitterns, and coraciforms) were too scanty to allow a meaningful analysis.

We distinguished six taxonomic groups of birds that include taxa of similar size, appearance, and habits and for the sake of simplicity called them by short English names thatfrom the point of view of avian systematics - are not always strictly correct: (i) "Ducks" - two thirds of the remains belonged to ducks (Anatidae) of the genera Anas, Aythya, Melanitta, and Bucephala and one third of the remains represented the coot Fulica atra which belongs to Rallidae but is 
often mistaken for a duck due to its habits and general appearance; (ii) "Partridges" - genera Alectoris and Perdix; (iii) "Pigeons"- almost all remains belonged to the genus Columba, usually to C. livia, but some bones of Streptopelia are also included; (iv) "Corvids" - the group includes only the jackdaw Corvus monedula and choughs of the genus Pyrrhocorax; other corvids were excluded from the taphonomic analysis because they do not nest in caves; (v) "Starlings" - Sturnus probably S. vulgaris, but other starling species were usually not excluded; and (vi) "Passerines"technically speaking, corvids and starlings are also passerines, but this group includes only small species of the genera Alauda, Calandrella, Carduelis, Coccothraustes, Emberiza, Eremophila, Fringilla, Galerida, Hirundinidae, Lanius, Melanocorypha, Montifringilla, Parus, Petronia, and Phoenicurus.

Although not very numerous and not quite homogenous, remains of diurnal birds of prey and owls form an additional group that we decided to study to see whether raptors were also preyed upon by other raptors, hunted by people, or died a natural death at the site.

Eight types of long bones were analyzed, which are coracoid, humerus, ulna, radius, carpometacarpus, femur, tibiotarsus, and tarsometatarsus. Only in the case of Passerines was the radius not identified to species, and therefore, it was not included in the analysis of that group of birds. The presence of other skeletal elements was only noted, but we did not study them in detail.

The humerus and tibiotarsus of two most numerous prey groups (Partridges and Pigeons) were checked for possible breakage patterns typical of the Eagle Owl. The owls tend to cut off the proximal part of the humerus and tibiotarsus and leave the shaft attached to the distal parts (De Cupere et al. 2009).

Bone ratio of the wing to leg elements was calculated as the number of wing elements (humerus, ulna, carpometacarpus) divided by the sum of wing and leg elements (femur, tibiotarsus, tarsometatarsus), expressed as a percent (Ericson 1987; Livingston 1989).

All remains were examined under a light microscope using strong directional light to find any possible surface modifications done by humans (cut marks, traces of burning) and animals (traces of digestion, punctures and perforations, gnawing marks). The marrow cavities of broken long bones were checked for possible medullary bone that would indicate females during egg laying (Serjeantson 1998, 2009; Van Neer et al. 2002), but no bones were snapped on purpose and no drilling on complete bones was performed. Based on the relative porosity of bone surface, each specimen was also classified into one of the following two categories: fully ossified (adult) or not fully ossified (subadult or immature).

Color alterations of bones may represent traces of burning (Stiner et al. 1995), and therefore, all such instances were recorded. Only carbonized bones that were black not only on the surface but also throughout the thickness of the bone were considered as traces of burning; speckled and patchy discolorations that were present only on the bone surface were recorded as mineral staining (Stiner et al. 1995). Burn color codes described by Stiner et al. (1995) were used to describe the extent of burning damage of particular specimens, which are 0 -not burned, 1 - slightly burned (localized and $<$ half carbonized), 2-lightly burned (>half carbonized), and 3fully carbonized (completely black). Higher code stages (4 6) refer to bone calcination (white color) that was not observed in Sarakenos Cave. Special attention was paid to possible traces of burning localized on articular ends because they may indicate dismembering of the carcass prior to grilling; an articular end of a bone that had been separated from another bone is exposed directly to the fire, while the rest of the bone is still covered by meat, skin, and feathers (Cassoli and Tagliacozzo 1997; Cain 2005; Laroulandie 2005a; Bochenski and Tomek 2010).

Traces of digestion on proximal and distal epiphyses and also on diaphysis can be in the form of pits, holes, or perforations with rounded edges; the surface of breakage affected by digestion is also smooth, thinned, and rounded - it may look like a piece of plastic where the edges have melted in heat (Bochenski and Tomek 1997; Bochenski 2005). Breakages of the shaft were considered altered through digestion even if only their portions were rounded because it may well have happened that a part of the bone broke off after the bone had been deposited. Although the effects of soil corrosion are similar to digestion, they can be distinguished from digestion by their lack of specific localization on the bone-corrosion can be found all over the bone, whereas digestion affects mostly articular ends and breakage surfaces (Andrews 1990; Bochenski and Tomek 1997; Fernandez-Jalvo and Andrews 1992).

It has been shown that punctures or perforation of bones made with claws and/or beaks of raptors while handling their prey are found on many skeletal elements; on long bones, they are typically located near the articular ends, regardless of the species of raptor and prey (Bochenski and Tornberg 2003; Bochenski et al. 2009; Laroulandie 2000, 2002).

\section{Results}

All skeletal elements — including long bones, axial skeleton, vertebrae, and phalanges - were found at Sarakenos Cave. Sterna or pelves were represented by small fragments, whereas long bones were somewhat better preserved. The only body parts that were extremely scarce were the cranial elements (brain case, beak, and mandible). Two thirds of the 2328 remains retrieved from the assemblage belonged to two taxonomic groups, which are Partridges $(\mathrm{NISP}=800)$ and Pigeons 
(NISP $=764$ ). Three taxonomic groups - Corvids, Starlings, and Passerines - yielded about 200 specimens each, whereas Ducks provided only a little more than a hundred remains (data pooled for all bones and periods; Table 1).

All skeletal elements, regardless of the taxonomic group and period, are heavily fragmented. Many remains show cracks, are rather fragile, and need to be handled carefully; in fact, fresh breakages were often observed. Complete specimens make up only $22 \%$ (NISP $=503$ ) of all the bones examined (NISP $=2328$; Table 1). The least fragmented element was the carpometacarpus (53\% of all carpometacarpi were complete), followed by the coracoid ( $30 \%$ complete) and the tasometatarsus (27\% complete; data pooled for all taxa and periods). The most heavily affected element was the tibiotarsus (1\% complete), followed by the radius ( $7 \%$ complete) and the femur (10\% complete). Particular taxonomic groups differed in the degree of breakage; Corvids and Ducks yielded very few complete bones (10 and 12\%, respectively), Pigeons and Partridges had approximately twice as many complete bones (19 and 20\%, respectively), whereas the highest share of complete bones was among Starlings and Passerines (36 and 41\%, respectively; data pooled for all elements and periods). Regarding the three periods distinguished, the Paleolithic and Neolithic are similar in the degree of breakage (19 and 23\% of complete long bones, respectively), whereas the Mesolithic showed somewhat better preservation (28\% complete; data pooled for all taxa and skeletal elements).

In Partridges, most proximal ends of the humerus and tibiotarsus were separated from the shaft just below the articulation, whereas the distal ends were usually connected to the remaining shaft (Fig. 2). In Pigeons, the fragmentation was more complicated; most proximal ends of the humerus were preserved in a similar manner as in Partridges (i.e., without adjoining shaft), but no clear pattern was visible in distal humerus (fragments with shaft were equally numerous as those without it). In the tibiotarsus, both ends (proximal and distal) preserved better with shaft.

Wing elements predominated over leg elements in all but one taxonomic group; in Passerines, the preponderance was extremely high, whereas in other groups, it was high to moderate (Fig. 3). The only taxonomic group with a reverse tendency (leg bones slightly predominated) was the Corvids.

Perforations attributable to claws and/or beaks of raptors were recorded on average in 5\% of remains (data pooled for all taxa, skeletal elements, and periods; Table 2 and Fig. 4). Remains of four taxonomic groups (Ducks, Partridges, Corvids, and Starlings) were affected by perforation in the same degree (4\% each), whereas two other groups showed somewhat higher degree of perforation (Pigeons-6\%, Passerines-8\%; data pooled for all skeletal elements and periods). No differences in the degree of perforation were observed between particular periods; on average, $5 \%$ of bones were perforated in the Paleolithic, Mesolithic, and Neolithic (data pooled for all taxa and skeletal elements). There are some differences between particular skeletal elements. Wing elements tend to be more often perforated than the leg bones (humerus-15\%, ulna $-8 \%$, and carpometacarpus- $5 \%$ versus femur $-3 \%$, tibiotarsus $-2 \%$, and tarsometatarsus $-2 \%$; data pooled for all taxa and periods). More than half (51\%) of all perforations were located on proximal ends of bone, with distal ends and shafts being less frequently affected (31 and $21 \%$, respectively; data pooled for all taxa and skeletal elements). In a few cases, perforations were located on the edge of broken bones that originated from the same specimenthey took the form of semi-circular indentations on each corresponding fragment, and they were recognizable only when the two fragments of bone were fitted together (Fig. 4b, d).

Traces of digestion were recorded on $38 \%$ of remains (data pooled for all skeletal elements, taxa, and periods; Table 2 and Fig. 5). On average, such traces were less frequently observed on wing bones than on leg elements (humerus-37\%, ulna$40 \%$, carpometacarpus-39\% versus femur- $54 \%$, tibiotarsus - $45 \%$, tarsometatarsus- $31 \%$ ). Traces of digestion were recorded on both articular ends (proximal and distal) and on the surface of breakage but were nearly absent on shafts (data pooled for all skeletal elements, taxa, and periods). The share of remains affected by digestion decreased with the age, Paleolithic (42\%), Mesolithic (29\%), and Neolithic (19\%; data pooled for all taxa and skeletal elements). Remains of particular taxonomic groups were affected by digestion in similar extent, ranging between 33\% (Corvids) and $43 \%$ (Ducks); the only exception were Starlings, whose remains were more seldom affected (24\%; data pooled for all skeletal elements and periods).

Regarding possible traces of human activity, not a single cut mark was recorded on any specimen. Color alteration of bone (black bones, brownish or blackish patches or spots) was observed on several dozen specimens, but only eight bones were carbonized and therefore could be treated as burned (data pooled for all taxa, skeletal elements, and periods; Fig. 6). The burned bones come from all three periods (Table 3 ). It is worth noting that two of the eight burned bones also had traces of digestion (Fig. 7c, d).

Medullary bone was recorded in 11 specimens that include Partridges (2), Pigeons (3), Corvids (4), Starlings (1), and Passerines (1). The bones were retrieved from all three periods, which are Paleolithic, Mesolithic, and Neolithic, and they represent four various types of elements, which are scapula (1), ulna (4), femur (2), and tibiotarsus (4) (Table 4 and Fig. 7a, b). Four fragments with medullary bone (Partridges, Pigeons, and Corvids) also had traces of digestion.

On average, $8 \%$ of the remains (NISP $=189$ ) were not fully ossified and therefore represented immature or subadult individuals (data pooled for all taxa, skeletal elements, and periods; Table 5). Three taxonomic groups (Partridges, 


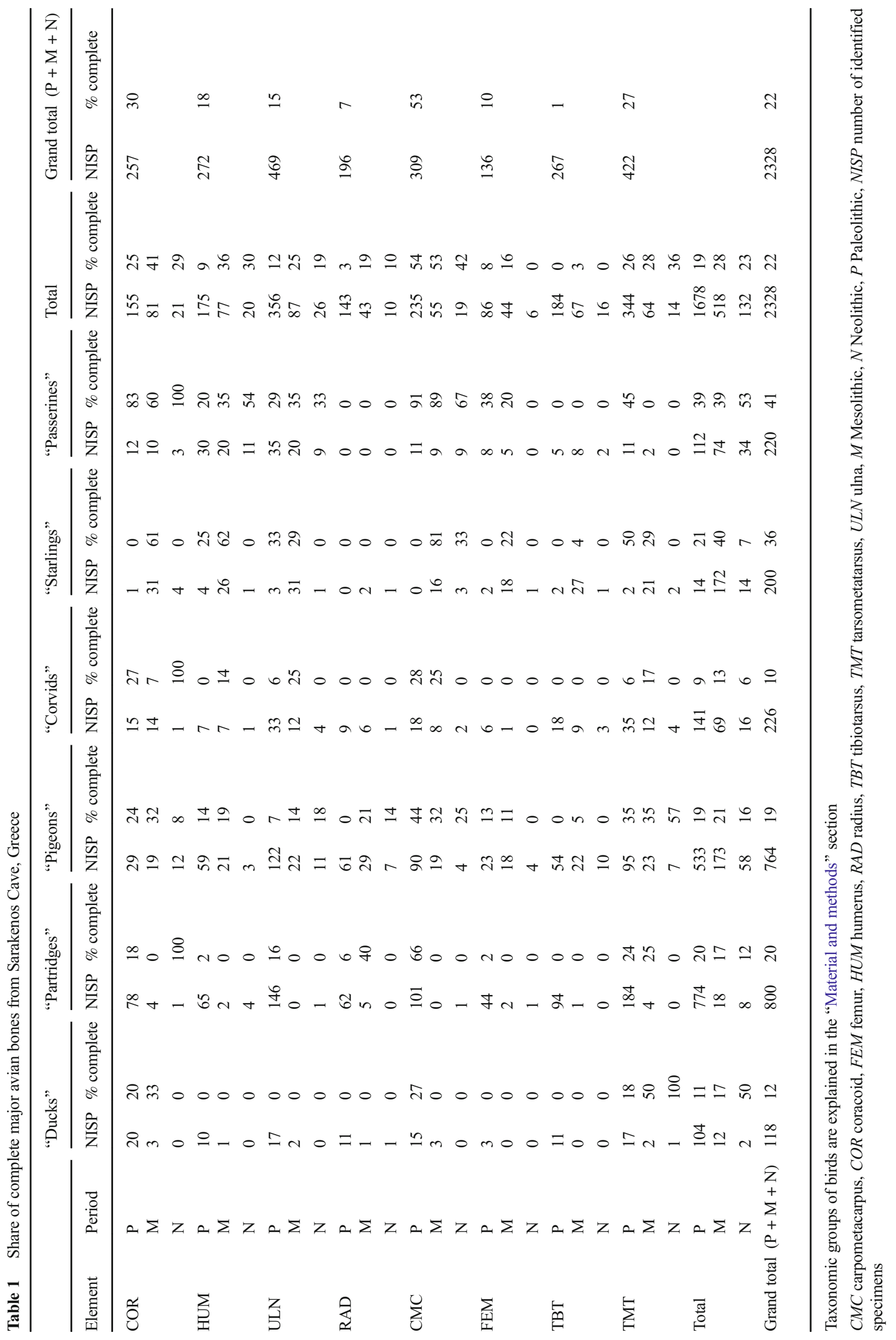



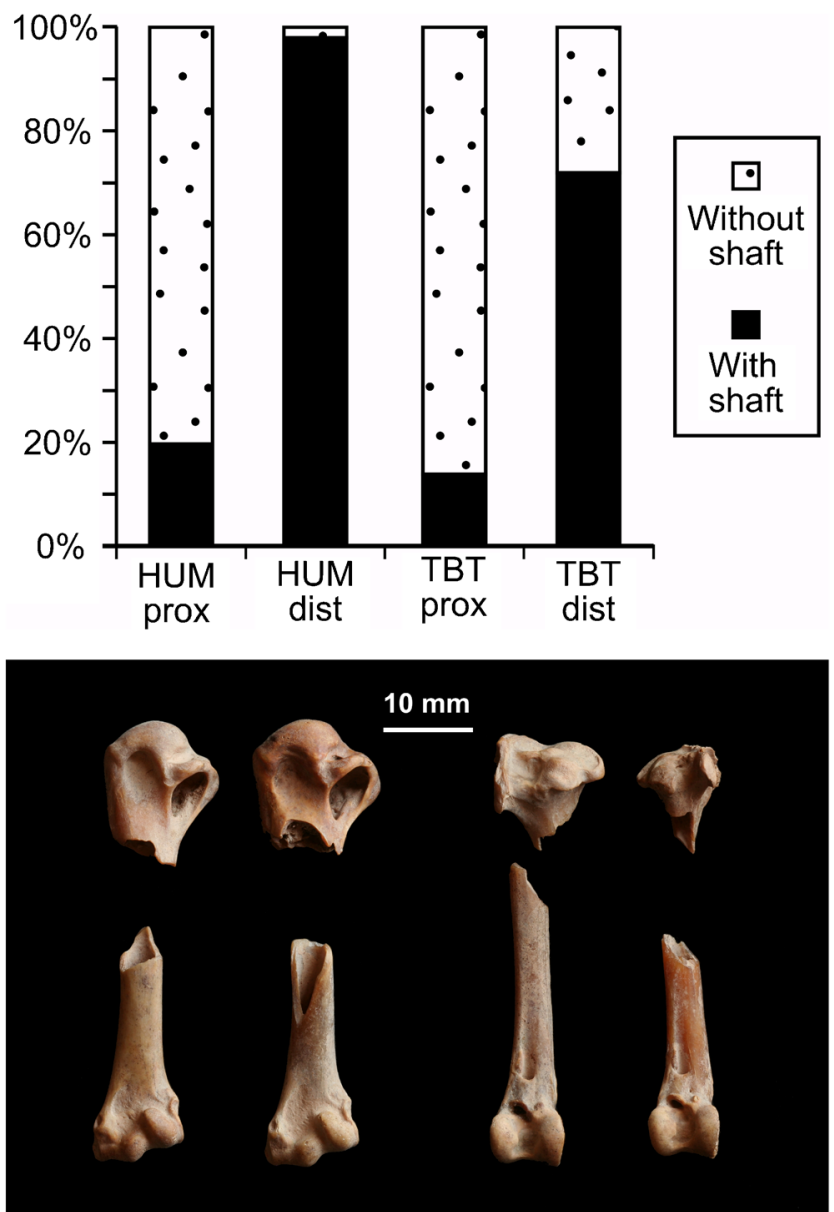

Fig. 2 Fragmentation pattern in the humerus and tibiotarsus of "Partridges"; most proximal ends of the two bones are separated from the shaft just below the articulation, whereas the distal ends are usually connected to the remaining shaft

Pigeons, and Corvids) provided relatively many unossified remains, but only the latter two were recorded in all three periods. The share of subadult Ducks,Starlings, and Passerines was very small. The share of immature specimens increased with the archeological age; it was lowest in the

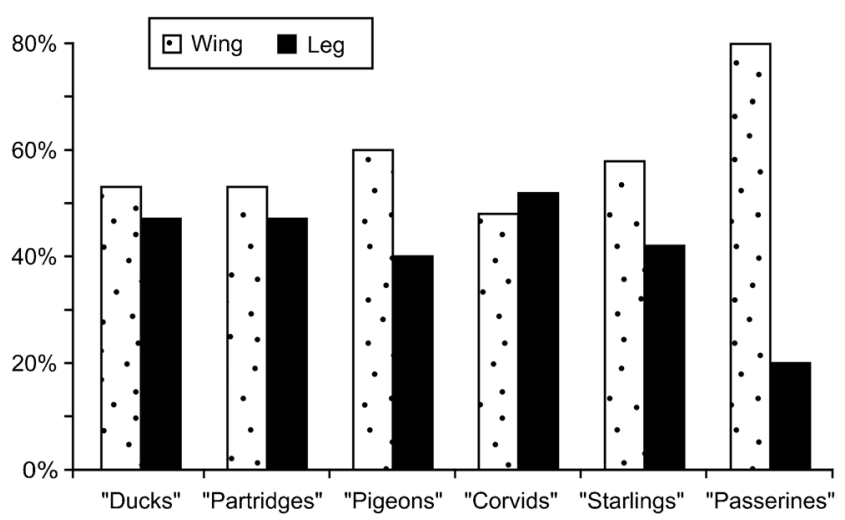

Fig. 3 Proportion of the total number of wing (humerus, ulna, carpometacarpus) to leg (femur, tibiotarsus, tarsometatarsus) bones in six taxonomic groups distinguished in Sarakenos Cave
Paleolithic (5\%), more than twice as great in the Mesolithic (13\%), and even higher in the Neolithic (17\%). Subadult specimens of diurnal birds of prey were found only in the Paleolithic (at least 3 species, NISP $=13$ ), and they outnumbered subadult remains of owls that were found in the Paleolithic and Mesolithic (2 species, NISP = 3).

Eight taxa of diurnal birds of prey and six taxa of owls were recorded at Sarakenos Cave (Table 6). A great majority of the remains were retrieved from the Paleolithic levels. Traces of digestion were observed on $46 \%$ of all the remains and perforations on $10 \%$ (data pooled for all taxa, skeletal elements, and periods). Neither cut marks nor any traces of burning were recorded on these specimens.

\section{Discussion}

The species composition in Sarakenos Cave is noteworthy. The number of avian species retrieved from each individual period was high or very high (Paleolithic - 78, Mesolithic41, Neolithic-19), and the species ranged from tits and other small passerines, through medium-sized pigeons and partridges to relatively large ducks and birds of prey (Wilczyński et al. 2016a; unpublished data from trench D). While it is rather unlikely that Final Paleolithic people hunted many small birds for food, they could exploit birds of medium and large size such as pigeons, partridges, or ducks (Serjeantson 2009). In fact, it has already been suggested that Final Paleolithic inhabitants of Sarakenos Cave were responsible for the accumulation of partridge remains and waterfowl (Kaczanowska et al. 2016a; Wilczyński et al. 2016a, b). Yet, the previous studies based the assumptions solely on the fact that partridges and waterfowl were relatively numerous in the sediment and caves are outside the habitat range of the taxa - no hard evidence was reported. Therefore, we decided to address the problem in greater detail.

Direct evidence of human activity that can be found on avian bones includes cut marks and traces of burning (Laroulandie 2005b; Serjeantson 2009). In the case of avian remains, cut marks are recorded relatively seldom even if other lines of evidence indicate that the birds in question are human food remains (Serjeantson 2009; Steadman et al. 2002). Such sites as La Vache (Laroulandie 2005a) or Taï 2 (Louchart and Soave 2002) with high percentages of remains with cut marks are rare. Cuts on avian bones tend to be more frequent on Paleolithic sites that are located in high latitudes because carcasses may have been dried or frozen at the time that they were butchered (Serjeantson 2009, p. 163). Since Sarakenos Cave is located in southern Europe, the lack of cut marks on avian remains may not necessarily mean that people were not involved.

The eight carbonized bones may represent fire-induced changes. The remaining specimens with brownish or blackish 


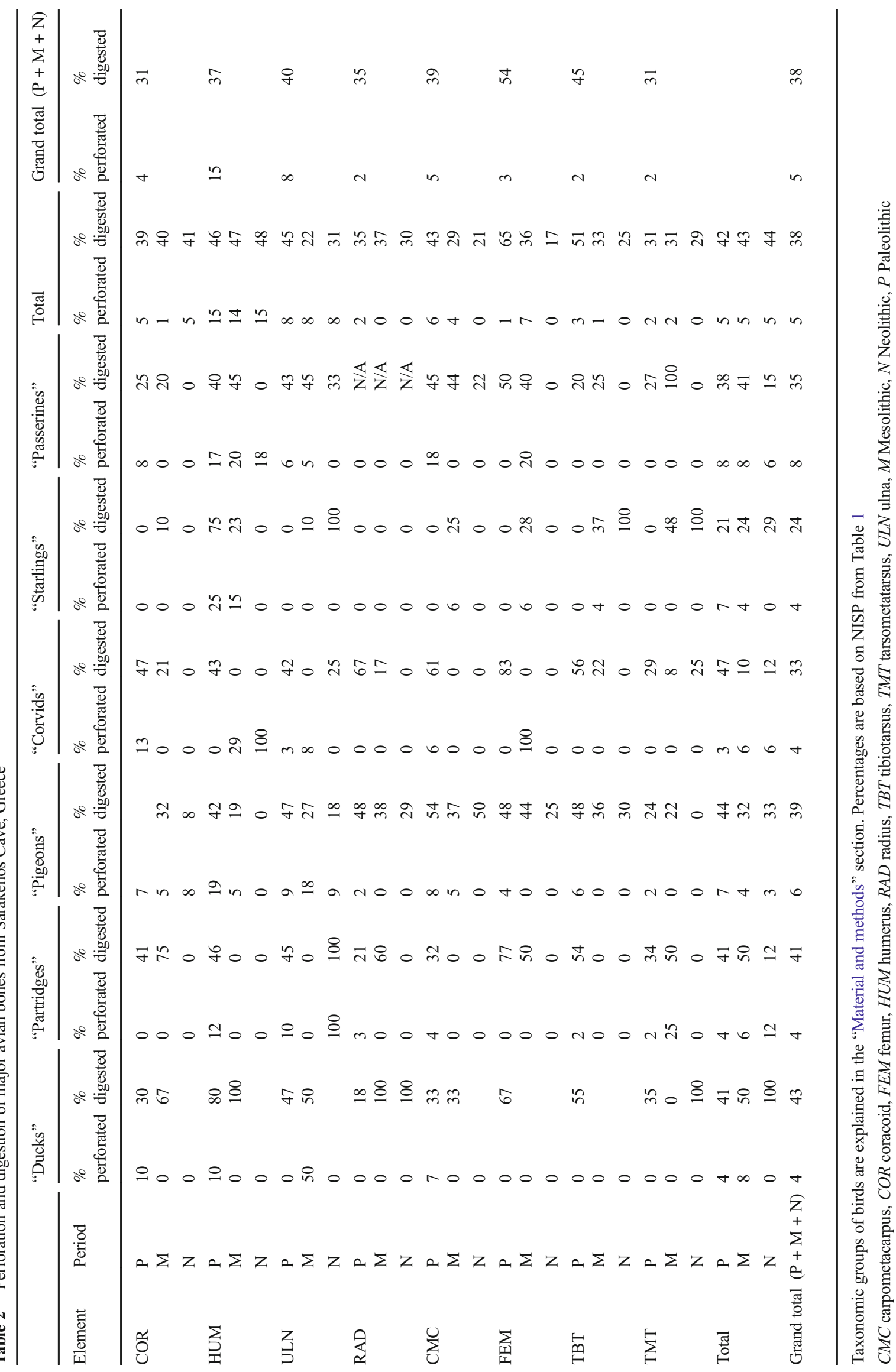


Fig. 4 Perforations of proximal humeri attributable to owls' claws and/or beak. a, b "Partridges." c, d "Pigeons." Perforations may weaken the bone and increase its fragmentation. Arrows in $\mathbf{b}, \mathbf{d}$ indicate the breakage lines that go across the perforations (the fragmented bones were glued together)

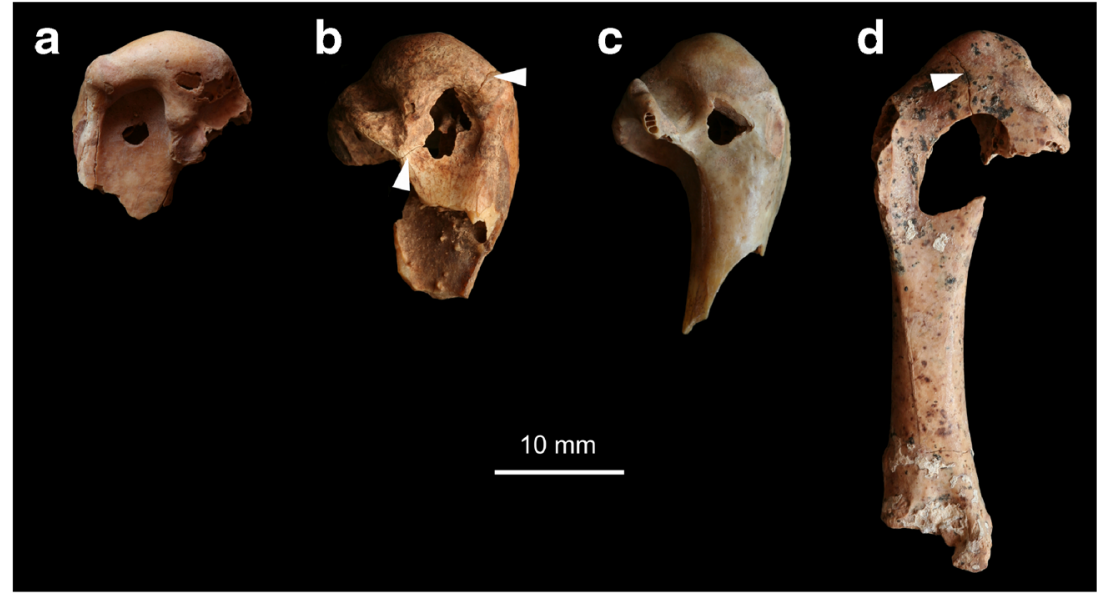

patches probably result from mineral staining such as manganese and/or iron oxides (Shahack-Gross et al. 1997) and thus have nothing to do with fire. Even the bones that were damaged by fire could have been burned accidentally because they happened to have been buried in close proximity to a later fire (Stiner et al. 1995). The very low rate of possible burning in present study would be also consistent with accidental burning (Stiner and Munro 2011). A crucial aspect of the present interpretation is that two of the eight carbonized remains also had traces of digestion. Obviously, the bones were first swallowed and exposed to digestive juices of predators and only later were discolored by fire.

The very high degree of fragmentation of avian remains in Sarakenos Cave makes any analysis of relative preservation difficult. For a long time, the remains were exposed to trampling by people who frequently visited the cave and also by sheep and goat that were kept there in later times (Sampson 2008a). Therefore, many remains have been broken after they had been deposited, which additionally hampers taphonomic analyses. For this reason, we decided to check only the most frequently applied wing versus leg element ratio and skip the others. The wing/leg ratio is believed to differentiate between human food remains where meat-rich leg bones prevail and natural decomposition factors where leg bones are underrepresented (Ericson 1987). Avian remains derived from owl pellets and uneaten food remains of diurnal raptors are characterized either by an equal proportion of the wing and leg elements or - more often - by the predominance of wing elements (Bochenski 2005; Lloveras et al. 2014). Although heavily fragmented and therefore more prone to misinterpretation, the remains from Sarakenos Cave fit the "owl pellet" category. Certainly, they differ considerably from the human food remains because leg elements in Sarakenos are in minority. Wing elements also prevailed among bird remains from the Roman bath complex in Sagalassos, Turkey, and subAtlantic deposits in the Ural Mountains - both of which were attributed to the Eagle Owl (De Cupere et al. 2009; Bochenski and Nekrasov 2001, respectively). The fact that remnants of many skeletal elements, including vertebrae and phalanges, were recorded at the site also indirectly supports their owl or diurnal raptor pellet origin (Bochenski 2005; Lloveras et al. 2014), while the almost total lack of cranial elements suggests
Fig. 5 Traces of digestion in the form of extensive pitting of distal (a) and proximal (b) humerus and rounding of broken shaft edges of another humerus. All bones belong to "Partridges" of the genus Alectoris. Besides digestion, a distinct perforation is visible at the base of the proximal part (b)

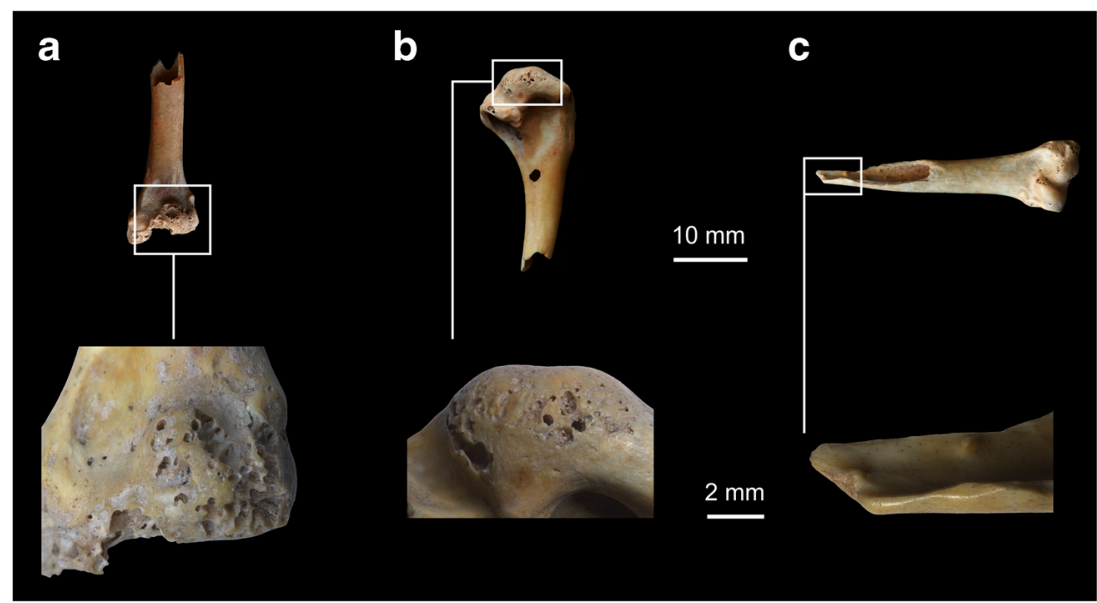


Fig. 6 Bones with color alterations that may represent fire-induced changes. a Completely black carbonized proximal ulna of the jackdaw Corvus monedula. b Partly blackened carbonized proximal carpometacarpus of Corvus/ Pyrrhocorax. c Proximal femur of Alectoris, with black patches on the bone surface that can be attributed to mineral staining rather than burning
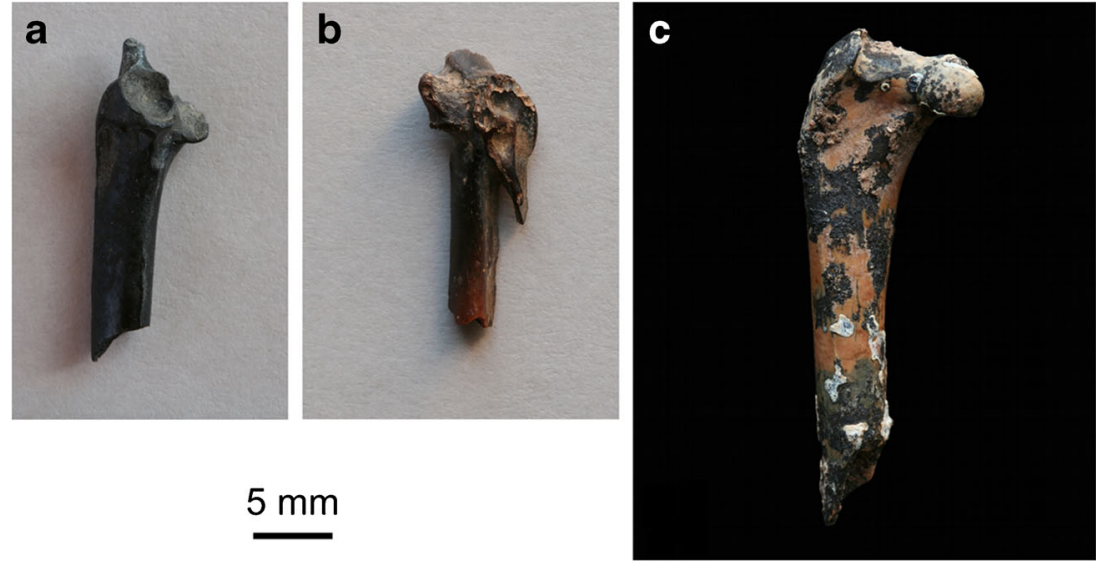

\section{$5 \mathrm{~mm}$}

the Eagle Owl, which is known to decapitate its prey prior to swallowing (Glutz von Blotzheim and Bauer 1980; Bochenski et al. 1993).

The fragmentation of the humerus and tibiotarsus of Partridges follows the pattern produced by the Eagle Owls (De Cupere et al. 2009). The proximal part of the humerus is typically cut off at its base, which coincides with the location of perforations or holes made by the owl's beak (see next paragraph). This is the way the Eagle Owl separates the wings from the main body of its prey (Bochenski 1960; Bochenski et al. 1993). It is hard to say why in Pigeons the pattern does not work so well (only the proximal humerus agrees with this pattern). One of the possible explanations is that not all Pigeons were preyed upon by Eagle Owls; some may have died in the cave of natural reasons and their bones preserved differently. Here, we can only speculate; more studies on more numerous remains would be necessary to solve the problem.

Qualitatively, perforation of bones observed in Sarakenos Cave is consistent with perforations done by owls and diurnal raptors; the shape and size of holes correspond to those made by contemporary owls and raptors (Bochenski and Tornberg 2003; Bochenski et al. 2009; Laroulandie 2000, 2002). Also, the location of punctures on long bones (near the articular ends) agrees with those made by both modern raptors and

Table 3 The number of (partly) carbonized specimens that represent fire-induced changes in Sarakenos Cave

\begin{tabular}{lllll}
\hline Taxon & Paleolithic & Mesolithic & Neolithic & Total \\
\hline "Ducks" & 2 (both 2) & $1(3)$ & - & 3 \\
"Partridges" & - & - & - & - \\
"Pigeons" & $1(2)$ & $2(1$ and 2$)$ & - & 3 \\
"Corvids" & - & $1(3)$ & $1(3)$ & 2 \\
"Starlings" & - & - & - & - \\
"Passerines" & - & - & - & - \\
Total & 3 & 4 & 1 & 8 \\
\hline
\end{tabular}

In brackets are burn color codes according to the classification of Stiner et al. (1995) owls (see above citations) including those of the Eagle Owl from the Roman baths in Turkey (De Cupere et al. 2009). The humerus was the most frequently affected bone both in Sarakenos Cave and in food remains of various species of owls and diurnal raptors. The only difference is in the percentage of punctured bones; in Sarakenos Cave, the percentage was rather low, which can be (partly) explained by the high degree of fragmentation (perforated bones may have suffered more fragmentation).

Traces of digestion in Sarakenos Cave correspond well with those made by owls (Bochenski 2005; Bochenski and Tomek 1997; Bochenski et al. 1998). They are observed on articular ends of long bones and on the surface of breakages, whereas shafts are not affected. The degree of digestion damage is much larger in remains extracted from pellets of diurnal raptors (Bochenski 2005; Lloveras et al. 2014). A similar pattern of damage through digestion was also observed on Eagle Owl food remains from the Roman bath complex in Sagalassos, Turkey (De Cupere et al. 2009).

Remains of diurnal birds of prey and owls do not differ from other avian remains found in Sarakenos Cave. Bones of raptors and owls were affected by perforation and digestion in similar proportions to remains of other birds, which suggests that they were deposited by the same agent(s). The most probable species responsible for the accumulation of raptor and owl remains is the Eagle Owl, which may nest at the entrance to caves and which hunts other species of owls and many diurnal raptors that try to share its range (Cramp et al. 1985). In fact, our results from Sarakenos Cave agree with those of a study of the diet and nest site characteristics of the Eagle Owl in northern Greece (Papageorgiou et al. 1993). The southwestern exposure of the entrance to the cave is preferred by the Eagle Owls. Also, the reported diet includes many species recovered from Sarakenos Cave, including some of the diurnal raptors and owls (Papageorgiou et al. 1993).

The specimens that are not fully ossified represent birds that must have bred locally. Some of them could even have nested in Sarakenos Cave (pigeons, owls, choughs, jackdaws), and they may have died there of natural causes. In fact, the 


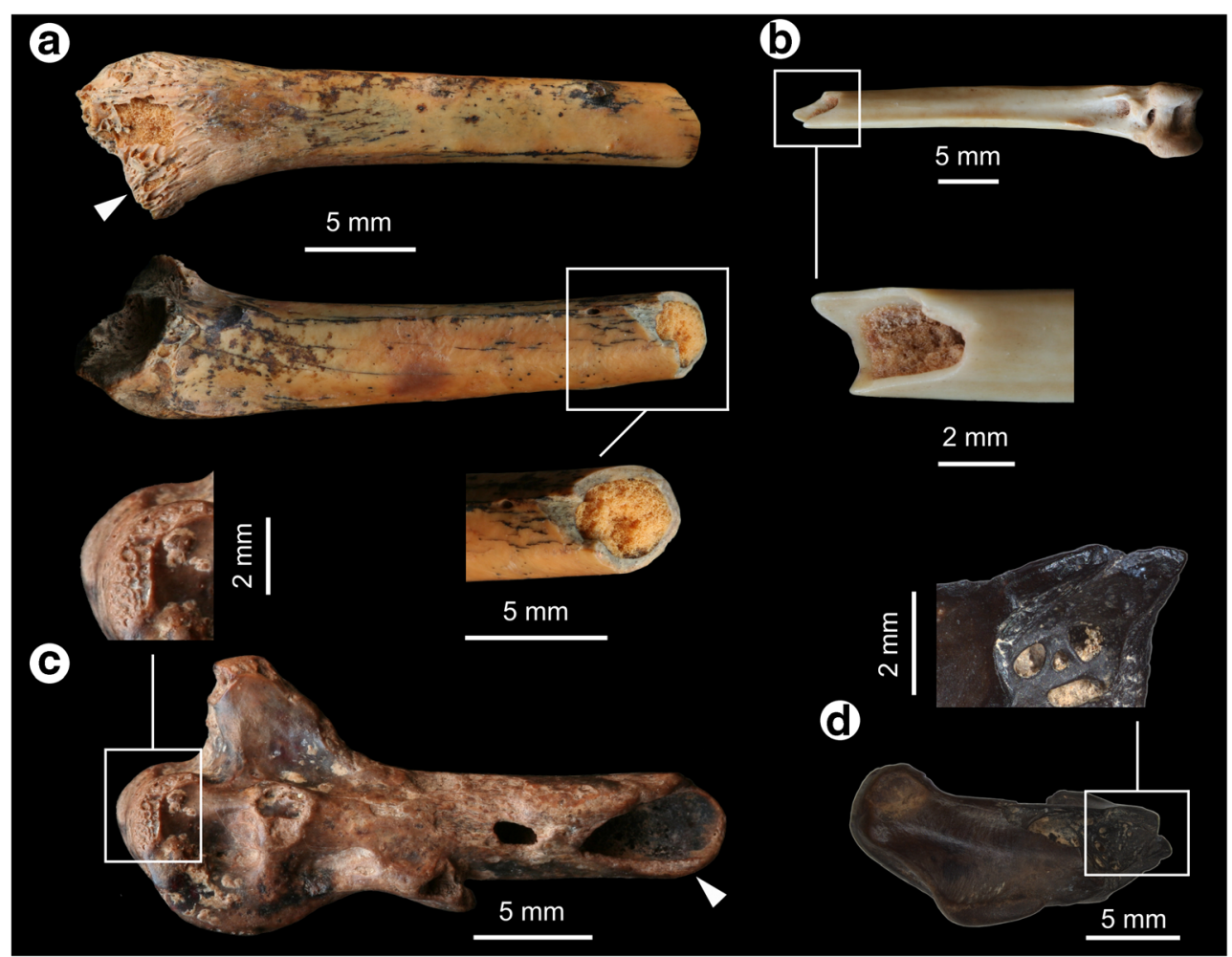

Fig. 7 Traces of digestion observed on specimens with medullary bone $(\mathbf{a}, \mathbf{b})$ and discolored bones (c, d). a Proximal ulna of a jackdaw Corvus monedula in caudal (top) and cranial (bottom) views. Arrow indicates the proximal part affected by digestion, medullary bone shown in enlarged fragment of freshly broken shaft. b Distal tibiotarsus of an unidentified member of "Corvids." The shaft cavity is filled with medullary bone, and the breakage has distinctly rounded edges due to digestion. c Proximal

large proportion of young chough remains, together with the fact that no cut marks or other human-derived evidence was recorded, was interpreted in favor of natural death in the rock shelter of Vaufrey, France (Laroulandie 2000, p. 175). Although this may well have been the case in Sarakenos Cave, an alternative explanation is also possible; young,

Table 4 Specimens with medullary bone found in Sarakenos Cave

\begin{tabular}{llll}
\hline Period & Taxon & Element & Digestion \\
\hline Paleolithic & "Partridges" & Ulna & \\
& & Femur & + \\
Mesolithic & "Corvids" & Ulna & \\
& & Ulna & \\
& & Ulna & + \\
& & TBT & + \\
Neolithic & "Starlings" & Femur & \\
& "Pigeons" & Scapula & \\
& & TBT & \\
& & TBT & + \\
\hline
\end{tabular}

Some of the bones also showed traces of digestion carpometacarpus of an unidentified member of "Ducks." Black discoloration penetrates deep into the bone, and therefore, it may represent fire-induced changes; digestion is visible as pitting in the proximal part (enlargement) and rounding of broken shaft edges (arrow). d Scapular end of coracoid of an unidentified member of "Ducks." Digestion is visible as rounding of broken shaft edges

inexperienced birds would also be an easy prey of owlssimilarly to predator-naïve juvenile hares that are preyed upon

Table 5 The number of immature specimens with not fully ossified bones in Sarakenos Cave

\begin{tabular}{lllll}
\hline Taxon & Paleolithic & Mesolithic & Neolithic & Total \\
\hline "Ducks" & 8 & 0 & 0 & 8 \\
"Partridges" & 32 & 3 & 0 & 35 \\
"Pigeons" & 25 & 29 & 15 & 69 \\
"Corvids" & 16 & 31 & 8 & 55 \\
"Starlings" & 1 & 1 & 0 & 2 \\
"Passerines" & 3 & 1 & 0 & 4 \\
Subtotal & 85 & 65 & 23 & 173 \\
Falco tinnunculus & 7 & 0 & 0 & 7 \\
Falco subbuteo & 3 & 0 & 0 & 3 \\
Falco vespertinus & 2 & 0 & 0 & 2 \\
Falco middle size & 1 & 0 & 0 & 1 \\
Athene noctua & 1 & 0 & 0 & 1 \\
Tyto alba & 0 & 2 & 0 & 2 \\
Subtotal & 14 & 2 & 0 & 16 \\
Grand total & 99 & 67 & 23 & 189 \\
\hline
\end{tabular}


Table 6 Perforation and digestion of bones of owls and diurnal birds of prey

\begin{tabular}{|c|c|c|c|c|c|c|c|c|c|c|c|c|}
\hline \multirow[t]{2}{*}{ Species } & \multicolumn{3}{|c|}{ Paleolithic } & \multicolumn{3}{|c|}{ Mesolithic } & \multicolumn{3}{|c|}{ Neolithic } & \multicolumn{3}{|l|}{ Total } \\
\hline & NISP & $\begin{array}{l}\% \\
\text { digested }\end{array}$ & $\begin{array}{l}\% \\
\text { perforated }\end{array}$ & NISP & $\begin{array}{l}\% \\
\text { digested }\end{array}$ & $\begin{array}{l}\% \\
\text { perforated }\end{array}$ & NISP & $\begin{array}{l}\% \\
\text { digested }\end{array}$ & $\begin{array}{l}\% \\
\text { perforated }\end{array}$ & NISP & $\begin{array}{l}\% \\
\text { digested }\end{array}$ & $\begin{array}{l}\% \\
\text { perforated }\end{array}$ \\
\hline Accipiter gentilis & 2 & 50 & 0 & 0 & 0 & 0 & 0 & 0 & 0 & 2 & 50 & 0 \\
\hline Accipiter nisus & 1 & 0 & 0 & 0 & 0 & 0 & 0 & 0 & 0 & 1 & 0 & 0 \\
\hline Buteo rufinus & 2 & 0 & 0 & 0 & 0 & 0 & 0 & 0 & 0 & 2 & 0 & 0 \\
\hline Buteo sp. & 1 & 0 & 0 & 0 & 0 & 0 & 0 & 0 & 0 & 1 & 0 & 0 \\
\hline Falco cf. eleonore & 1 & 0 & 0 & 0 & 0 & 0 & 0 & 0 & 0 & 1 & 0 & 0 \\
\hline Falco peregrinus & 4 & 50 & 25 & 0 & 0 & 0 & 0 & 0 & 0 & 4 & 50 & 25 \\
\hline Falco sp. & 4 & 25 & 0 & 0 & 0 & 0 & 0 & 0 & 0 & 4 & 25 & 0 \\
\hline Falco subbuteo & 3 & 67 & 0 & 0 & 0 & 0 & 0 & 0 & 0 & 3 & 67 & 0 \\
\hline Falco tinnunculus & 26 & 69 & 12 & 0 & 0 & 0 & 0 & 0 & 0 & 26 & 69 & 12 \\
\hline Falco vespertinus & 12 & 42 & 17 & 0 & 0 & 0 & 0 & 0 & 0 & 12 & 42 & 17 \\
\hline Asio flammeus & 7 & 57 & 0 & 0 & 0 & 0 & 0 & 0 & 0 & 7 & 57 & 0 \\
\hline Asio otus & 1 & 0 & 0 & 1 & 0 & 0 & 0 & 0 & 0 & 2 & 0 & 0 \\
\hline Asio $\mathrm{sp}$. & 2 & 0 & 0 & 0 & 0 & 0 & 0 & 0 & 0 & 2 & 0 & 0 \\
\hline Athene noctua & 23 & 39 & 4 & 1 & 100 & 100 & 1 & 0 & 0 & 25 & 40 & 8 \\
\hline Bubo sp. & 4 & 0 & 0 & 0 & 0 & 0 & 0 & 0 & 0 & 4 & 0 & 0 \\
\hline Strix aluco & 3 & 100 & 0 & 0 & 0 & 0 & 0 & 0 & 0 & 3 & 100 & 0 \\
\hline Tyto alba & 0 & 0 & 0 & 4 & 0 & 50 & 0 & 0 & 0 & 4 & 0 & 50 \\
\hline $\begin{array}{l}\text { Strigiformes middle } \\
\text { size }\end{array}$ & 1 & 100 & 100 & 1 & 100 & 0 & 0 & 0 & 0 & 2 & 100 & 50 \\
\hline Total & 97 & 47 & 8 & 7 & 29 & 43 & 1 & 0 & 0 & 105 & 46 & 10 \\
\hline
\end{tabular}

NISP number of identified specimens

by the Great Horned Owls in North America (Rohner and Krebs 1996).

Medullary bone is found in the bones in females just before and during the time of lay. In the domestic chicken, it is most common in the femur and tibiotarsus and least common in the tarsometatarsus and humerus (Serjeantson 2009; Van Neer et al. 2002), but it is rarely observed in wild species on archeological sites (Serjeantson 2009). Our study confirms that medullary bone is often laid down in the tibiotarsus of wild species and that it happens in other elements including the ulna and scapula, but our sample was too small to draw farreaching conclusions. To the best of our knowledge, the four fragments with medullary bone that also had traces of digestion are probably the first bones ever reported that bear simultaneously the two conditions. They indicate that the breeding females were hunted by the owls that nested and/or roosted in Sarakenos Cave. Since breeding season takes place in spring, we can conclude that humans did not visit the cave at that time because it is very unlikely that any owl would nest in the cave while it was used by people. Of course, people could have visited Sarakenos Cave in spring but not in the same years as the owls, which agrees with the notion that human groups only visited the cave but not inhabited it permanently (Kaczanowska et al. 2016b). Indeed, the seasonality of occupation suggested by dental cementum analysis of the sheep/ goat teeth that had partially complete annual growth bands indicates that the visits of human groups evidenced in layers 3 and 2 took place in summer or at the spring/summer transition (Wilczyński et al. 2016b), but for reasons mentioned above, it does not contradict our results.

Our results suggest that bird remains from Sarakenos Cave are more likely to have been deposited by owls rather than diurnal birds of prey, mammalian carnivores, or humans. Diurnal raptors can be excluded because animal remains in their pellets are nearly always heavily digested (Bochenski 2005; Lloveras et al. 2014), which was not the case in Sarakenos Cave. Mammalian carnivores consume bones or at least heavily damage them and leave bite marks (Andrews 1990), which we did not observe on the remains. Likewise, we did not manage to find much evidence of human-induced modifications on the avian bones; the eight carbonized bones could have been burned accidentally. The moderate degree of digestion, punctures in bones, predominance of wing elements, and rich species composition indicate owls. The species of owls that occur in Greece include the Barn Owl Tyto alba, Common Scops Owl Otus scops, Eagle Owl Bubo bubo, Little Owl Athene noctua, Tawny Owl Strix aluco, Long-eared Owl Asio otus, Short-eared Owl Asio flammeus, and Tengmalm's Owl Aegolius funereus (Lambert 1957). With the exception of the Eagle Owl, all other owls feed mainly 
on small animals and they take larger prey only exceptionally (Cramp et al. 1985; Alivizatos et al. 2005). On the other hand, the Eagle Owl prefers prey of medium size such as pigeons and partridges that dominate the avian assemblage of Sarakenos Cave. In fact, the diet of the Eagle Owl includes enormous range of bird species from small passerines that are taken rather infrequently up to full-grown herons and birds of its own species (Cramp et al. 1985; Papageorgiou et al. 1993). All the lines of evidence taken together strongly suggest that the most likely raptor responsible for the accumulation of many of the remains is the Eagle Owl that would have nested and/or roosted at the entrance to the cave. Smaller owl species that prey upon smaller prey could also occasionally contribute to the assemblage. Some individuals of cave-dwelling species like pigeons, choughs, or owls could have died of natural reasons. Also, some remains could represent human food remains but we are unable to prove it.

Our proposition to explain the predominance of avifauna among animal remains with causes other than those related to bird hunting by human groups visiting the cave corresponds well with the modest amount of material relics left by these groups. This leads us to the conclusion that during the Final Paleolithic and Mesolithic, the cave was only incidentally used as a short-term hunting shelter, while in the Initial and Early Neolithic, it played the role of a short-term shelter for herdsmen. It is not before the Middle Neolithic that we have evidence for the cave having been used as a cult site.

Acknowledgments The paper was presented at the ICAZ Taphonomy Working Group meeting, Paris, France, 2016. The study of archeological sequence and finds from Sarakenos Cave has been supported by Polish National Science Centre (NCN) grant no. 2015/19/B/HS3/00477.

\section{Compliance with ethical standards}

Conflict of interest The authors declare that they have no conflict of interest.

Open Access This article is distributed under the terms of the Creative Commons Attribution 4.0 International License (http:// creativecommons.org/licenses/by/4.0/), which permits unrestricted use, distribution, and reproduction in any medium, provided you give appropriate credit to the original author(s) and the source, provide a link to the Creative Commons license, and indicate if changes were made.

\section{References}

Alivizatos H, Goutner V, Zogaris S (2005) Contribution to the study of the diet of four owl species (Aves, Strigiformes) from mainland and island areas of Greece. Belg J Zool 135:109-118

Andrews P (1990) Small mammal taphonomy. In: Lindsay EH, Fahlbusch V, Mein P (eds) European Neogene mammal chronology. Plenum Press, New York, pp 487-494

Bochenski Z (1960) The diet of the eagle-owl Bubo bubo (L.) in the Pieniny Mts. Acta Zool Cracov 5:311-333
Bochenski ZM (2005) Owls, diurnal raptors and humans: signatures on avian bones. In: O'Connor T (ed) Biosphere to Lithosphere: New studies in vertebrate taphonomy [Proceedings of the 9th Conference of the International Council of Archaeozoology, Durham 23-28 august 2002]. Oxbow Books, Oxford, pp 31-45

Bochenski ZM, Nekrasov AE (2001) The taphonomy of sub-Atlantic bird remains from Bazhukovo III, Ural Mountains, Russia. Acta Zool Cracov 44:93-106

Bochenski ZM, Tomek T (1997) Preservation of bird bones: erosion versus digestion by owls. Int J Osteoarchol 7:372-387

Bochenski ZM, Tomek T (2009) A key for the identification of domestic bird bones in Europe: preliminary determination. Institute of Systematics and Evolution of Animals-Polish Academy of Sciences, Kraków

Bochenski ZM, Tomek T (2010) The birds of Klisoura Cave 1: a window into the Upper Palaeolithic Greece. Eurasian Prehistory 7:91-106

Bochenski ZM, Tornberg R (2003) Fragmentation and preservation of bird bones in uneaten food remains of the gyrfalcon Falco rusticolus. J Archaeol Sci 30:1665-1671

Bochenski ZM, Tomek T, Boev Z, Mitev I (1993) Patterns of bird bone fragmentation in pellets of the Tawny Owl (Strix aluco) and the Eagle Owl (Bubo bubo) and their taphonomic implications. Acta Zool Cracov 36:313-328

Bochenski ZM, Huhtala K, Jussila P, Pulliainen E, Tornberg R, Tunkkari PS (1998) Damage to bird bones in pellets of gyrfalcon Falco rusticolus. J Archaeol Sci 25:425-433

Bochenski ZM, Tomek T, Tornberg R, Wertz K (2009) Distinguishing nonhuman predation on birds: pattern of damage done by the whitetailed eagle Haliaetus albicilla, with comments on the punctures made by the golden eagle Aquila chrysaetos. J Archaeol Sci 36: 122-129

Cain CR (2005) Using burned animal bone to look at middle stone age occupation and behavior. J Archaeol Sci 32:873-884

Cassoli PF, Tagliacozzo A (1997) Butchering and cooking of birds in the Palaeolithic site of Grotta Romanelli (Italy). Int J Osteoarchol 7: 303-320

Cramp S, Brooks DJ, Dunn E, Gillmor R, Hollom PAD, Hudson R, Nicholson EM, Ogilvie MA, Olney PJS, Roselaar CS, Simmons KEL, Voous KH, Wallace DIM, Wattel J, Wilson MG (1985) Handbook of the birds of Europe, the Middle East, and North Africa: the birds of the western Palearctic, vol. IV: terns to woodpeckers. Oxford University Press, Oxford

De Cupere B, Thys S, Van Neer W, Ervynck A, Corremans M, Waelkens M (2009) Eagle Owl (Bubo bubo) pellets from Roman Sagalassos (SW Turkey): distinguishing the prey remains from nest and roost sites. Int J Osteoarchol 19:1-22

Ericson PG (1987) Interpretations of archaeological bird remains: a taphonomic approach. J Archaeol Sci 14:65-75

Fernandez-Jalvo Y, Andrews P (1992) Small mammal taphonomy of Gran Dolina, Atapuerca (Burgos), Spain. J Archaeol Sci 19:407428

Glutz von Blotzheim UN, Bauer KM (eds) (1980) Handbuch der Vögel Mitteleuropas, vol. 9: Columbiformes-Piciformes. Academische Verlagsgesellschaft, Wiesbaden

Kaczanowska M, Kalicki T, Kozłowski JK, Moskal del Hoyo M, Wilczyński J (2016a) Conclusions. In: Kaczanowska M, Kozłowski JK, Sampson A (eds) The Sarakenos Cave at Akraephnion, Boeotia, Greece, vol. II: the Early Neolithic, the Mesolithic and the Final Palaeolithic. Polish Academy of Arts and Sciences, Kraków, pp 133-136

Kaczanowska M, Kozłowski JK, Sampson A (eds) (2016b) The Sarakenos Cave at Akraephnion, Boeotia, Greece, vol. II: the Early Neolithic, the Mesolithic and the final Palaeolithic. Polish Academy of Arts and Sciences, Kraków

Lambert A (1957) A specific check list of the birds of Greece. Ibis 99:4368 
Laroulandie V (2000) Taphonomie et Archéozoologie des Oiseaux en Grotte: Applications aux Sites Paléolithiques du Bois-Ragot (Vienne), de Combe Saunière (Dordogne) et de La Vache (Ariège). Dissertation, Université Sciences et Technologies-Bordeaux I

Laroulandie V (2002) Damage to pigeon long bones in pellets of the Eagle Owl Bubo bubo and food remains of peregrine falcon Falco peregrinus: zooarchaeological implications. Acta Zool Cracov 45: 331-339

Laroulandie V (2005a) Bird exploitation pattern: the case of Ptarmigan Lagopus sp. in the Upper Magdalenian site of La Vache (Ariège, France). In: Grupe G, Peters J (eds) Feathers, grit and symbolism: Birds and humans in the ancient Old and New Worlds [Documenta Archaeobiologiae 3: Proceedings of the 5th Meeting of the ICAZ Bird Working Group, Munich, 26-28 July 2004]. Verlag Marie Leidorf, Rahden/Westf, pp. 165-178

Laroulandie V (2005b) Anthropogenic versus non-anthropogenic bird bone assemblages: new criteria for their distinction. In: O'Connor $\mathrm{T}$ (ed) Biosphere to Lithosphere: New studies in vertebrate taphonomy [Proceedings of the 9th Conference of the International Council of Archaeozoology, Durham 23-28 august 2002]. Oxbow Books, Oxford, pp: $25-30$

Livingston SD (1989) The taphonomic interpretation of avian skeletal part frequencies. J Archaeol Sci 16:537-547

Lloveras L, Thomas R, Lourenço R, Caro J, Dias A (2014) Understanding the taphonomic signature of Bonelli's eagle (Aquila fasciata). J Archaeol Sci 49:455-471

Louchart A, Soave R (2002) Changement d'ampleur de l'exploitation des oiseaux entre le Magdalénien et l'Azilien: l'exemple du Taï 2 (Drôme) [difference in the extent of the exploitation of birds between the Magdalenian and Azilian: the example of Taï 2 (Drôme)]. Quaternaire 13:297-312

Papageorgiou NK, Vlachos CG, Bakaloudis DE (1993) Diet and nest site characteristics of Eagle Owl (Bubo bubo) breeding in two different habitats in north-eastern Greece. Avocetta 17:49-54

Perlès C (1990) Les industries lithiques taillées de Franchthi (Argolide, Grèce), Tome II: Les industries du Mésolithique et du Néolithique initial. Indiana University Press, Bloomington

Rohner C, Krebs CJ (1996) Owl predation on snowshoe hares: consequences of antipredator behaviour. Oecologia 108:303-310

Sampson A (2008a) A brief geographical and historical review. In: Sampson A (ed) The Sarakenos cave at Akraephnion, Boeotia, Greece, vol. I: the Neolithic and the bronze age. University of the Aegean-Polish Academy of Arts and Sciences, Athens, pp 19-24

Sampson A (ed) (2008b) The Sarakenos Cave at Akrephnion, Beotia, Greece, vol. I: the Neolithic and the Bronze Age. University of the Aegean-Polish Academy of Arts and Science, Athens

Sampson A, Kozłowski JK, Kaczanowska M, Budek A, Nadachowski A, Tomek T, Miękina B (2009) Sarakenos Cave in Boeotia, from
Palaeolithic to the Early Bronze Age. Eurasian Prehistory 6:199231

Sampson A, Kaczanowska M, Kozłowski JK (2010) The prehistory of the island of Kythnos (Cyclades, Grece) and the Mesolithic settlement at Maroulas. Polish Academy of Arts and SciencesUniversity of Aegean, Kraków

Serjeantson D (1998) Birds: a seasonal resource. Environ Archeol 3:2333

Serjeantson D (2009) Birds. Cambridge University Press, Cambridge

Shahack-Gross R, Bar-Yosef O, Weiner S (1997) Black-coloured bones in Hayonim Cave, Israel: differentiating between burning and oxide staining. J Archaeol Sci 24:439-446

Spyropoulos T (1973) Contribution to the study of Kopais area. Athens Annals of Archaeology 6:201-208

Steadman DW, Plourde A, Burley DV (2002) Prehistoric butchery and consumption of birds in the Kingdom of Tonga, South Pacific. J Archaeol Sci 29:571-584

Stiner MC, Munro ND (2011) On the evolution of diet and landscape during the Upper Paleolithic through Mesolithic at Franchthi Cave (Peloponnese, Greece). J Hum Evol 60:618-636

Stiner MC, Kuhn SL, Weiner S, Bar-Yosef O (1995) Differential burning, recrystallization, and fragmentation of archaeological bone. $\mathrm{J}$ Archaeol Sci 22:223-237

Tomek T, Bochenski ZM (2000) The comparative osteology of European corvids (Aves: Corvidae), with a key to the identification of their skeletal elements. Institute of Systematics and Evolution of Animals - Polish Academy of Sciences, Kraków

Tomek T, Bochenski ZM (2009) A key for the identification of domestic bird bones in Europe: Galliformes and Columbiformes. Institute of Systematics and Evolution of Animals-Polish Academy of Sciences, Kraków

Van Neer W, Noyen K, De Cupere B, Beuls I (2002) On the use of endosteal layers and medullary bone from domestic fowl in archaeozoological studies. J Archaeol Sci 29:123-134

Wilczyński J, Tomek T, Nadachowski A, Miękina B, Rzebik-Kowalska B, Pereswiet-Soltan A, Stworzewicz E, Szyndlar Z, Marciszak A, Lõugas L (2016a) Faunal record and environmental changes during Holocene and Pleistocene. In: Kaczanowska M, Kozłowski JK, Sampson A (eds) The Sarakenos Cave at Akraephnion, Boeotia, Greece, vol. II: the Early Neolithic, the Mesolithic and the Final Palaeolithic. Polish Academy of Arts and Sciences, Kraków, pp 63-80

Wilczyński J, Tomek T, Pryor A (2016b) Archaeozoological record. In: Kaczanowska M, Kozłowski JK, Sampson A (eds) The Sarakenos Cave at Akraephnion, Boeotia, Greece, vol. II: the Early Neolithic, the Mesolithic and the Final Palaeolithic. Polish Academy of Arts and Sciences, Kraków, pp 81-90 